\title{
LA INFLUENCIA NEERLANDESA EN LAS MENINAS DE VELÁZQUEZ
}

\author{
THE DUTCH INFLUENCE \\ ON LAS MENINAS BY VELÁZQUEZ
}

\author{
Francisco Javier Navarro Moragas \\ Escuela de Arte de Sevilla. España \\ ORCID: 0000-0003-0390-4622 \\ javiernavarro@exegetas.com
}

\begin{abstract}
Superado aquel aspecto nacionalista y diferenciador que la historiografía del siglo XIX quiso destacar en la producción artística europea que le precedió, hoy escogemos comprender las mutuas interinfluencias que dieron origen a unas manifestaciones artísticas que fueron tejidas en el telar de una Europa compartida. Este trabajo apunta a considerar las influencias que la producción pictórica y el posicionamiento intelectual de los Países Bajos del Siglo de Oro ejercieron sobre la obra maestra de uno de los pintores más relevantes del siglo XVII europeo: Las Meninas, de Diego Rodríguez de Silva y Velázquez.

Palabras clave: Las Meninas; Velázquez; Holanda; Países Bajos; influencia.
\end{abstract}

Having overcome the differentiating and nacionalistic aspects that the $19^{\text {th }}$ century's historiography wanted to emphasize in European artistic production that preceded it, we nowadays prefer to understand the mutual influences that gave origin to the artistic manifestations which were woven into the painting of a shared Europe. This research aims to considerate the influences that the pictorial production and the intelectual positioning of the Dutch Golden Age exercised over the masterpiece of one of the most relevant painters of $17^{\text {th }}$ century Europe: Las Meninas by Diego Rodríguez de Silva y Velázquez.

Keywords: Las Meninas; Velázquez; Holland; The Low Countries; influence.

Son tantas las voces acreditadas que escribieron sobre Las Meninas que, al afrontar nuevas aproximaciones, la pluma por fuerza se intimida; pero no por ello se abstiene de ser fiel al impulso de sus propias intuiciones, siempre y cuando queden argumentadas. En este trabajo expondremos una serie de circunstancias que apuntan a la influencia que sobre el lienzo de Las Meninas de Velázquez pudo ejercer la pintura neerlandesa del Siglo de Oro. 
Es singular, en Las Meninas, la configuración del espacio arquitectónico. Singular por desacostumbrada en la pintura española del seiscientos. La sencillez espacial de la estancia, "que es la del quarto del Príncipe, donde se finge, y donde se pintó" , define un espacio en forma de paralelepípedo del que solo vemos una mitad, ya que el propio cuadro ubica al espectador en la otra media. Las aristas en el encuentro de muros, suelo y techo son perpendiculares o, en su caso, paralelas al plano del cuadro, dejando así el muro al fondo en vista frontal. La serenidad de los planos arquitectónicos alivia la tensión compositiva de la mitad inferior. Al fondo, unos cuadros, dos puertas, un espejo y una suerte de repisa bajo él se ordenan en estricta ortogonalidad. El resultado es un espacio inusual en la pintura española del seiscientos, pero sí recurrente en la pintura de los Países Bajos de los Habsburgo, especialmente en la zona septentrional. Esa disposición aparece en La familia De Goyer y el pintor (1650-1655), del neerlandés Adriaen van Ostade. Del mismo modo, pero compositivamente más próximo a Las Meninas, se presenta en Mujer y niño junto a una ventana y sirvienta limpiando (hacia1655), de Pieter de Hooch. También De Hooch, en El portador de malas noticias (hacia 1655), exhibe una disposición arquitectónica similar con amplia visión del techo de la estancia como en Las Meninas. Por su parte, el también neerlandés Jan Miense Molenaer construye en Retrato de la familia del pintor tocando música (hacia 1635) (Figura 1) la misma configuración, siendo además un "retrato de grupo", género que aunque afín a la pintura neerlandesa no es compartido por la España del Barroco. Y, no obstante, es un elemento narrativo fundamental en Las Meninas. Encontramos la misma configuración espacial en otra pieza de Molenaer, Alegre compañía (1631), donde además la techumbre, como en el lienzo de Madrid, se muestra ostensiblemente. Otras muchas obras neerlandesas presentan estos mismos registros espaciales y compositivos. El pintor Pieter Janssens Elinga, flamenco pero afincado en Amsterdam, representa en La muchacha del collar de perlas (1623-1682) un espacio cúbico de planos perpendiculares y un muro de fondo en el que los contornos ortogonales del mobiliario y la puerta abierta, amén de la techumbre, recuerdan en mucho el espacio de habitabilidad de la tela española. También de Elinga es Interior con pintor, mujer leyendo y sirvienta limpiando (1668) (Figura 2), donde además de la ortogonalidad espacial aparecen: en primer lugar, una puerta al fondo, abierta a un espacio al otro lado del muro; en segundo lugar, la esperada simetría ortogonal de los objetos al fondo; y, en tercer lugar, un espejo. Su ubicación centrada en los elementos murales nos remite, junto a lo demás, a la composición del lienzo español. En la tela Mujer leyendo una carta (1665), Gabriël Metsu construye un espacio similar y reincide en el motivo del espejo al fondo. La luz difusa que baña la escena proviene de un vano perpendicular al cuadro, como en la mayoría de los ejemplos citados,

${ }^{1}$ Palomino, 1797: 509.

LABORATORIO DE ARTE 32 (2020), pp. 159-182, ISSN 1130-5762

e-ISSN 2253-8305 - DOI http://dx.doi.org/10.12795/LA.2020.i32.09 
y al igual también que en Las Meninas. El holandés Pieter de Hooch recurre con insistencia a los espacios cúbicos, muros frontales al fondo, elementos ubicados en red ortogonal, techumbres notorias, puertas abiertas que declaran una realidad más allá del espacio escénico principal, vanos de ventana en muros laterales por los que la luz tamizada anima la escena, y con frecuencia un espejo colgado sobre la pared frontal ${ }^{2}$. En su Interior con mujer cosiendo y niño (1668) (Figura 3), son de destacar los elementos que quedan parcialmente "fuera de cuadro", como ocurre con ciertos elementos escenográficos en Las Meninas de Velázquez. Y en Dama tocando el virginal de pie (hacia 1672), del holandés Johannes Vermeer, encontramos otro aspecto en relación al lienzo español: el diálogo entre lo que sucede en escena y la narrativa del cuadro que cuelga de la pared frontal; una estrategia dialógica enriquecedora del discurso y que justifica la obra. Un recurso que Velázquez utiliza en su obra principal.

La puerta abierta en el muro de fondo, tan usual en la pintura holandesa, es un recurso extraño al Barroco español. Y, no obstante, es parte del juego compositivo del lienzo del Prado, dotándolo de mayor profundidad espacial. En él, de un primer plano iluminado por la luz de un ventanal que no vemos pero se insinúa con la contraventana, pasamos a una ligera penumbra que afecta al propio pintor, envolviendo luego en mayor grado a las figuras de Marcela de Ulloa y del guardadamas - que Palomino en su Parnaso no identifica- hasta alcanzar la máxima umbría al fondo de la estancia. La puerta abierta declara, con su luminosidad, un espacio más allá del confín de la escena principal; y de no ser por la figura del aposentador esa luminosidad perjudicaría el equilibrio compositivo. Así, con una secuencia luz-sombra-luz, Velázquez consigue un efecto de "espacialidad extendida" por el que percibimos una ampliación del límite escenográfico. La figura del aposentador tiene una doble función; por un lado, mitiga el foco de luz, y, por otro, da noticia verosímil de las distancias ${ }^{3}$. En la producción pictórica neerlandesa del siglo XVII, la puerta, que sugiere una "espacialidad extendida", y la inclusión en ella de una figura humana de referencia son motivos recurrentes. David Teniers el Joven, en Los jugadores de cartas (1633), los utiliza para conectar

${ }^{2}$ Son muchas las obras que pueden ser citadas. Algunos de estos aspectos, por ejemplo, aparecen también en La visita (1657), de Pieter de Hooch. También de De Hooch, y participando en todo o en parte de las características citadas, son Mujer bebiendo con dos hombres (1658), El dormitorio (hacia 1659), Jugadores de cartas en habitación luminosa (1658), Interior con mujer leyendo y niño con aro (hacia 1664), La sala del Concejo del Ayuntamiento de Ámsterdam (hacia 1664) y también Interior con mujer junto a una cesta de ropa (1663).

${ }^{3}$ Con respecto a este punto, Muller dice que, "pese a las líneas de fuga que vemos en la pared de la derecha, no se tendría la ilusión de profundidad de la estancia si al fondo no se abriera una puerta fuertemente iluminada por la luz de otra estancia. [...] Y precisamente sería demasiado luminosa si ante el intenso claro no destacara la figura del aposentador de la reina”. Muller, 1975: 234. 
los personajes del espacio escénico principal con el personaje situado en el espacio "extraescénico". Algo similar sucede en El doctor de pueblo (1636), también de Teniers el Joven, donde el personaje al otro lado se afana en labores que se relacionan con las del primer plano. Por su parte, Jan Miense Molenaer nos presenta en Tres mujeres ante el virginal (1634) una escena de intimidad musical en familia donde, además del vano abierto al fondo, los personajes expresan su sorpresa por la presencia intrusiva del espectador, del mismo modo que sucede en Las Meninas. En ese mismo lienzo de Molenaer, un retrato de mujer cuelga del muro en testimonio más que de su ausencia, de su omnipresencia; al igual que sucede en el lienzo de Madrid con la imagen especular de Felipe IV y Mariana de Austria. En Familia campesina (hacia 1646), también de Molenaer, el personaje en el umbral de la puerta atempera, como en el lienzo de Velázquez, la luminosidad del espacio "extraescénico". Y en Pieter de Hooch, Interior con mujer y niño y sirvienta limpiando el patio (hacia 1655), el diálogo corporal que se establece entre el niño y la sirvienta, cada uno a un lado de la puerta que separa los espacios "intra" y "extraescénico", conecta dichos ámbitos, al igual que sucede en Las Meninas, donde el gesto contemplativo del aposentador conecta el espacio en el que se halla con lo que sucede en el interior del cuarto del Príncipe 4 .

En su mayoría, las obras comentadas, y otras muchas no citadas, insisten en una rigurosa organización ortogonal de los elementos contextuales -el elemento mobiliar- en el espacio vital, existencial -el elemento inmueble-, en contraste con cierta organicidad o insumisión de los elementos no pasivos de la escena-los

${ }^{4}$ De nuevo aquí los ejemplos que pueden citarse son muchos. En el lienzo de Adriaen Brouwer Campesinos fumando y bebiendo (hacia 1635), bajo el umbral de la puerta del fondo se recorta la figura de un personaje que conecta la escena principal con el espacio exterior sugerido. El recurso conecta con una tradición antigua del centro y norte de Europa. Así lo encontramos en una tabla tardogótica alemana de Derick Baegert, San Lucas pintando a la Virgen (hacia 1470), donde una puerta abierta en el muro de fondo deja ver a un ángel niño que se afana en su tarea, mientras que en el espacio escénico principal San Lucas retrata a la Virgen con el Niño, que posan para él. No queremos dejar de mencionar otras obras que datan o bien de 1656, año de ejecución de Las Meninas, o bien de fechas inmediatamente posteriores. En el primer caso, tenemos la obra Mujer joven dormida (hacia 1656), de Johannes Vermeer, en el que una puerta entreabierta al fondo del muro frontal separa el recogimiento del espacio principal, donde duerme la joven, de la estancia al otro lado. También de Vermeer es La callejuela (hacia 1657), en el que el vano se abre en la fachada de un edificio típicamente holandés, sugiriendo profundidad. Notable por la conexión entre el espacio de primer término y el extraescénico es la obra titulada El patio de una casa en Delft (1658), de Pieter de Hooch, donde los tamaños de las dos figuras declaran la distancia entre ellas. Otros autores holandeses como Jan Havicksz Steen y Emanuel de Witte pintaron espacios escénicos similares en lo que respecta a la ortogonalidad de los elementos, la frontalidad del muro de fondo con respecto al cuadro y, sobre todo, la puerta abierta que conecta los espacios cercano y lejano. 
personajes- ${ }^{5}$. Ese juego contrapuntístico conduce, sin embargo, a una concordancia armoniosa de voces contrapuestas que podemos apreciar en el lienzo de Las Meninas, del mismo modo que en la pintura neerlandesa de interior doméstico. Para Paloma Alarcó, ese estricto impulso reticular de la pintura holandesa del siglo XVII está en sintonía con "una noción de dignidad espiritual, un ascetismo estético y una concepción ética de la humanidad que muchas veces se ha

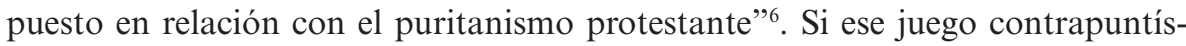
tico, si ese orden superior que aspira desde la racionalidad a ejemplarizar al género humano, está o no en relación con los impulsos rigoristas del protestantismo septentrional del siglo XVII, es algo que excedería del objetivo de este trabajo si no fuera porque podría implicar los posicionamientos del propio Diego Velázquez. Sin embargo, es más que probable que nunca sepamos de unas inclinaciones que, por peligrosamente heréticas en la España del seiscientos, habrían -si las hubo- de mantenerse en la más absoluta privacidad. De lo que no cabe duda es del escaso interés de nuestro pintor de corte por las temáticas contrarreformistas. Una indiferencia que percibimos en la calculada y apolínea belleza de su Cristo crucificado (hacia 1632), como también en su poco convincente -desde una posición piadosa-Cristo contemplado por el alma cristiana (1625), desprovisto de ardor místico, o también en el correcto academicismo de la Coronación de la Virgen (hacia 1635). Si los efluvios del movimiento reformista pudieron circular o no por entre la intelectualidad que acudió a las tertulias de Francisco Pacheco, despertando la curiosidad del joven Diego, quizás nunca lo sabremos. Pero del interés de Velázquez en su etapa sevillana por la estética y la temática de los Países Bajos dan cuenta su Vieja friendo huevos (hacia 1618), su Cristo en casa de Marta y María (1618) o La mulata (1618) cuando las ponemos en relación con Dos mujeres cocinando (1562), de Pieter Aertsen, con Cocina con naturaleza muerta (hacia 1630), de Frans Snyders, o con Cristo en casa de Marta y María (1565), de Joachim Beuckelaer. Este último con la representación al fondo de una escena extemporánea, que acompaña y da sentido a la escena principal, al igual que en los bodegones a lo divino del Velázquez de juventud. Pues, aunque común el tema de la vida doméstica a los territorios neerlandeses en su conjunto, los meridionales aspiraron a una sublimación que los conectase con sus creencias de fondo, como

5 Al describir la composición de Las Meninas dice Muller que, "de manera general, todo cuanto pertenece al ornato de esta estancia, todo lo circundante, posee una estructura rígida y rigurosa, mientras que los seres humanos aportan la flexibilidad y el calor (moderado) de la vida". Muller, 1975: 232. En ese sentido, Gudiol apunta que "los cuadros colgados, el espejo, la puerta abierta constituyen una ordenación de formas rectangulares que es el mejor apoyo para los sutiles arabescos que crean los ademanes de los personajes". Gudiol, 1982: 289.

${ }^{6}$ Alarcó, 2012: 10.

LABORATORIO DE ARTE 32 (2020), pp. 159-182, ISSN 1130-5762 e-ISSN 2253-8305 - DOI http://dx.doi.org/10.12795/LA.2020.i32.09 
en los bodegones del joven Velázquez ${ }^{7}$. Una afinidad con el arte de los Países Bajos que sin duda hubo de estar alentada por el propio Pacheco, quien también utilizó ese recurso en alguno de sus trabajos ${ }^{8}$.

Con respecto a la tendencia neerlandesa a la organización ortogonal de los elementos del cuadro, es de destacar que Paloma Alarcó haya observado una interesante conexión umbilical entre la pintura holandesa del siglo XVII y la corriente neoplasticista del periodo de entreguerras. En su comisariado de la exposición Mondrian, De Stijl y la tradición artística holandesa, celebrada en el Museo Thyssen-Bornemisza de Madrid en 2012, Alarcó establece vínculos entre artistas del Siglo de Oro holandés tales como Philips Koninck, Pieter de Hooch y Jacobus Vrel con los principales del grupo De Stijl: Piet Mondrian, Theo van Doesburg y Bart van der Leck ${ }^{9}$. En el texto del opúsculo editado con motivo de la muestra, Alarcó subraya la tendencia de las obras de unos y otros a comportarse "como un plano pictórico frontal bidimensional, organizado geométricamente". La nueva sensibilidad holandesa del seiscientos, continúa diciendo la comisaria, se aparta de los modelos italianos y se orienta hacia una "composición lógica y precisa de los elementos formales, más apropiado al espíritu de los países del norte. [...] Como consecuencia, el juego de marcos, rectángulos, o la sucesión de cuadros dentro del cuadro, responde a un vocabulario abstracto en torno al cual se articula la pintura que pasa a ser la representación de un mundo «fabricado», geometrizado a base de la superposición de múltiples representaciones”. De este modo, para ella, todo ese juego de ortogonalidades, planos de color primario y líneas sintéticas del neoplasticismo no supone una desavenencia con la tradición anterior sino precisamente una continuidad, esto es, el afloramiento de un eón ${ }^{10}$ que ha fluido constante por el aparato circulatorio del arte de los Países Bajos. Y acaba diciendo que, si "la geometría era para los miembros de De Stijl la garantía de una ley natural espiritual por encima de la diversidad de la naturaleza", el

${ }^{7}$ Para Enriqueta Harris, la fuente de la que Velázquez bebió fueron "the sixteenthcentury kitchen and market scenes with biblical subjects represented on a small scale in the background, associated in particular with the Netherlandish artists Pieter Aertsen and Joachim Beuckelaer" ("las escenas seicentistas de cocinas y mercados con escenas bíblicas representadas a pequeña escala en el fondo, relacionadas principalmente con los artistas neerlandeses Pieter Aertsen y Joachim Beuckelaer"). Harris, 2006: 274.

${ }^{8}$ Nos referimos al lienzo San Sebastián atendido por Santa Irene (1616), destruido en la guerra civil española.

${ }^{9}$ Una analogía que ha sido también vista por André Chastel. Refiriéndose a las estructuras compositivas de la pintura neerlandesa barroca dice que, "en la estructura abstracta proporcionada por las líneas, estaríamos tentados de ver un anuncio de Mondrian". Chastel, 2015: 47.

${ }^{10}$ Empleamos aquí el término eón en el sentido en que lo usa Eugenio d'Ors como manifestación de unas constantes humanas extendidas linealmente en el tiempo, y que pueden aparecer y desaparecer a lo largo de su trayectoria. D’Ors, 2002: 65. 
engañoso realismo de la pintura holandesa del Siglo de Oro, "más que representar el mundo real, se vale de determinadas «abstracciones» para transmitir ideas morales"11. Finalmente anotemos que el historiador Alexandre Cirici i Pellicer ya observó analogías estructurales compositivas entre Las Meninas y las obras del neoplasticismo holandés ${ }^{12}$. Si las influencias observadas en el lienzo de Madrid con respecto a la producción holandesa barroca son meramente estilísticas o son además expresión de una simpatía ideológica con un impulso moralizador de tono reformista es algo que, como hemos dicho, excede de los objetivos de este trabajo. Pero a la vista de las habilidades esteganográficas ${ }^{13}$ de Velázquez, esto es algo cuya consideración pudiera ser interesante en otro lugar.

Respecto a la escenografía de Las Meninas, consideremos ahora los elementos fragmentados, aquellos que aparecen parcialmente "fuera de cuadro". Uno de ellos es el lienzo sobre el que el pintor trabaja en algo que nunca veremos ${ }^{14}$. En su mayor parte fuera del límite del propio lienzo real, más que dar noticia de sí sugiere la existencia de una "realidad extendida" más allá del umbral del cuadro. En ese sentido, este efecto de "realidad extendida" está en paralelo con el de la puerta abierta al fondo, y así parece también que ocurre en las composiciones neerlandesas. Parece justificado el "fuera de cuadro" del lienzo, dada la poca noticia que su entero revés proporcionaría. Lo mismo con el fragmento de caballete. No obstante, la espalda y la pierna derecha de Nicolasico Pertusato quedan también "fuera de cuadro"15. El argumento para el "fuera de cuadro" del lienzo no es aplicable a Nicolasico, y la explicación plausible ahora es la de evitar, de algún modo, el efecto paralizador que hubiese producido una composición "obligada" a los límites del marco. No estando entonces ni los objetos -lienzo y caballeteni los personajes -Nicolasico- constreñidos a los bordes de la pintura, estos perceptivamente desaparecen, y súbitamente la "realidad visible" del cuadro se

11 En el mismo opúsculo editado con motivo de la exposición, la comisaria relaciona las tensiones sociales que en el siglo XVII holandés llevaron a una pintura serena y a unas composiciones de orden riguroso, con los motivos que tras la Gran Guerra del siglo XX conducirían a la quietud de las composiciones estrictamente ortogonales del neoplasticismo. Alarcó, 2012: 10.

12 Dice Bardi en sus comentarios a Las Meninas que, "a propósito del futurismo del cuadro, se han sorprendido (Cirici-Pellicer) analogías estructurales con la organización «neoplástica» del Broadway boogie woogie de Mondrian”. Bardi, 1970: 106.

${ }^{13}$ La esteganografía habilita la emisión de discursos ocultos a través de elementos portadores, de tal manera que solamente puedan ser descifrados por unos receptores iniciados en los códigos que se emplean.

${ }^{14}$ Dada la incerteza de que el reflejo especular provenga de la superficie del lienzo que Velázquez ejecuta.

${ }_{15}$ Incluso teniendo en cuenta la posición inicial de la pierna, según la imaginamos hoy por su arrepentimiento, el cuerpo de Nicolasico Pertusato hubiese quedado igualmente "fuera de cuadro". 
completa con una "realidad extendida" que, coyunturalmente, no podemos ver pero percibimos. El tercer objeto parcialmente "fuera de cuadro" es la contraventana en la zona superior derecha. A diferencia del lienzo o de Nicolasico, la noticia de la contraventana es narrativamente irrelevante. La única razón plausible es la de insistir en el efecto de "realidad extendida". Tales efectos escenográficos, que apuntan a la percepción de una realidad más allá de los bordes del cuadro, lo encontramos en Interior con madre e hijo y sirvienta limpiando (hacia 1655), de Pieter de Hooch, donde solo podemos ver la mitad de la gran chimenea. O también en Reunión de oficiales y sargentos de la caballería municipal (1633), de Frans Hals, donde los dos personajes de los extremos quedan parcialmente fuera del borde del lienzo. En La compañía del capitán Reinier Reael y el teniente Cornelis Michielsz (hacia 1635), también de Hals, aunque los personajes extremos evitan el "fuera de cuadro", sin embargo el estandarte a la izquierda solo se muestra sugerido, por las mismas razones que el revés del lienzo en Las Meninas. Del efecto "fuera de cuadro" abundan ejemplos en la pintura holandesa barroca y, solo por citar algunos artistas, además de Hooch o Hals, mencionemos a Jan Miense Molenaer, Adriaen van Ostade, Adriaen Brouwer, David Teniers el Joven y Samuel van Hoogstraten.

Los dos lienzos de Frans Hals mencionados en el párrafo anterior pertenecen al género de retrato de grupo, que se consolida como tal en los Países Bajos del seiscientos ${ }^{16}$. A ese mismo género pertenece Retrato de la familia del pintor tocando música (hacia 1635), de Jan Miense Molenaer (Figura 1), donde los personajes súbitamente sorprendidos sostienen la mirada del espectador, al igual que ocurre en Las Meninas. El Retrato de familia tocando música (1663), de Pieter de Hooch, no solo comparte con el lienzo de Madrid la condición de retrato de grupo, sino también la configuración cúbica del espacio, la puerta abierta al fondo de un muro paralelo al plano del lienzo, y los elementos que quedan parcialmente fuera de cuadro. Pero lo que sorprende en el lienzo del Prado es justamente el ser un retrato de grupo cuando en la España del XVII no existió tradición alguna en ese género. Es, de acuerdo a esta circunstancia, una singularidad en el panorama pictórico del Barroco español. Como dice Raquel Novero, Las Meninas es una "obra singular dentro de su género, por ser un retrato de grupo, tan escaso en España donde no existió durante el siglo XVII tradición de este tipo de pintura; tanto es así que solo podemos citar Las Meninas y El embajador danés de Lerche

${ }^{16}$ El género del retrato en grupo tiene su antecedente en las grandes composiciones de historia sagrada y en las familias de donantes adorando a una efigie de devoción. Por lo tanto, el retrato colectivo había estado supeditado a programas iconográficos religiosos. En los territorios septentrionales de los Países Bajos, y debido tanto a la creciente iconoclasia religiosa de la Reforma protestante como a los gustos de una nueva burguesía, afloran la pintura costumbrista -con escenas populares o de oficios- y el retrato privado o colectivo. 
y sus amigos, de Antolínez" ${ }^{17}$. A los cuales nosotros podríamos añadir La familia del pintor (1665), de Juan Bautista Martínez del Mazo, y la pintura mural Retrato de la familia real (hacia 1660), en las Descalzas Reales de Madrid, atribuida por algunos a un aventajado seguidor de Juan Carreño de Miranda ${ }^{18}$. Pero ninguna de estas dos obras son testimonio de un género que realmente no existió en la España del seiscientos puesto que, por un lado, el lienzo de Martínez del Mazo es obviamente una referencia directa al de su maestro Velázquez y no el resultado de un uso acostumbrado. Y, por otro lado, la pintura mural de las Descalzas Reales, aunque profana si se observa aisladamente, sin embargo solo se comprende considerada en contexto. Ubicada en la zona superior de uno de los muros de la escalera principal del convento, que disfrutaba del patronazgo de la familia real, está enfrentada a El Calvario, atribuido a Antonio de Pereda. La actitud contemplativa de la familia del monarca y su disposición frente a la obra de Pereda la justifica como escena de donantes ${ }^{19}$, quedando entonces descartado el tono profano de la representación ${ }^{20}$.

Al norte de los Países Bajos afloraron, por motivos culturales y religiosos, no solo el retrato individual privado y el retrato colectivo, sino también una pintura de género amable, al gusto de una burguesía de comerciantes, ora de escenas costumbristas, ora de oficios artesanos. Uno de los oficios cuya representación pictórica comenzó a cobrar predicamento fue el del pintor trabajando en su estudio. De fecha anterior a 1656, año de ejecución de Las Meninas, es El estudio del artista (1631), donde se representa al pintor preparando su utillaje mientras sus modelos esperan el momento de volver a sus posiciones, tal como aparece en el pequeño lienzo sobre el caballete. La obra es autoría del neerlandés Jan Miense Molenaer, al igual que Pintor en su estudio (hacia 1633), donde el artista sentado ante el caballete copia una vanitas. De Joos van Craesbeeck es El estudio del pintor (1655). El protagonista en todos estos casos es el lienzo en proceso, que vemos

17 Novero Plaza, 2007: 179-180.

18 Morán Turina, 2010: 48.

19 Para Morán Turina, la familia de Felipe IV en las Descalzas Reales aparece asomada "a ese fingido balcón que domina el hueco de la escalera y desde el que podían contemplar piadosamente las imágenes de la pasión que aparecen pintadas, frente por frente, al otro lado del hueco de la escalera". Morán Turina, 2010: 45.

${ }^{20}$ Otros ejemplos neerlandeses de retrato de grupo son el de Jan Miense Molenaer, Fröhliche Gesellschaft in einer Wirtsstube (1649), o los extraordinarios retratos colectivos de Frans Hals Reunión de oficiales y sargentos de la caballería municipal (1633), Retrato de una familia holandesa (1634), La compañia del capitán Reinier Reael y el teniente Cornelis Michielsz (hacia 1635) y Familia ante un paisaje (hacia 1646). Y, si citamos a Rembrandt, destaquemos Ronda de noche (1642) o también La lección de anatomía del Dr. Nicolaes Tulp (1632). De pocos años después de la ejecución de Las Meninas son Los regentes del Hospicio de Ancianos de Haarlem (1664), de Frans Hals, y Los síndicos de los pañeros (1662), de Rembrandt. 
de frente, pero no el artista. Sin embargo, la pose del pintor en El artista en su estudio (1635), de David Teniers el Joven, declara con orgullo la creciente dignidad del oficio de la pintura, y por ende la del pintor. La temática del pintor en pleno ejercicio de su arte, desprovista de justificación religiosa ${ }^{21}$, es frecuente en los Países Bajos del XVII, pero esencialmente inexistente en la España del Siglo de Oro. En Las Meninas, sin embargo, es un recurso narrativo fundamental. Es esta una significativa circunstancia que, sumada a las anteriores, acerca extraordinariamente la obra maestra de Velázquez a la órbita estética e intelectual del norte de los Países Bajos. De los contadísimos ejemplos españoles podemos citar Autorretrato con su padre (hacia 1630), de Jusepe Martínez; Vendedor de cuadros (hacia 1670), de José Antolínez; y La familia del pintor (1665), de Juan Bautista Martínez del Mazo, donde en el extremo derecho vemos al artista trabajando en un retrato de corte ${ }^{22}$. Sin embargo, ninguno de los tres apunta hacia una tendencia española de género. Y esto es así porque Jusepe Martínez pudo estar influenciado por las temáticas neerlandesas siendo su padre, al que homenajea en el cuadro, oriundo de los Países Bajos. Con respecto a Antolínez, su influencia neerlandesa queda sugerida si tenemos en cuenta El embajador danés de Lerche y sus amigos, citado más arriba, un inusual retrato de grupo en el panorama de géneros de la pintura española del seiscientos. Y en cuanto al lienzo de Martínez del Mazo, la escena de taller procede muy claramente del influjo directo de Las Meninas.

Pero de entre todas las escenas de taller neerlandesas, hay una que nos resulta especialmente sugerente. Cuando reparamos en Pintor pintando un retrato (hacia 1600-1650) (Figura 4), del neerlandés Joos van Craesbeeck, es fácil que acuda a nosotros la escena representada en Las Meninas. A pesar de la inferioridad técnica del lienzo de Craesbeeck, de su diferente proporción y tamaño, así como de su tono burlesco, encontramos sin embargo elementos que avivan la conexión. Tras una llamada de atención hacia los invitados alrededor de la mesa, la vista se desplaza a la figura del pintor, eje definitivo de la narración. La posición del lienzo sobre el caballete no nos permite ver lo que ejecuta, por lo que la atención entonces no recae en la obra, sino en el pintor. Los invitados se inclinan ligeramente en señal de reverencia, y uno de ellos ofrece un refrigerio en una pequeña bandeja. El espacio cúbico de la estancia se posiciona ortogonalmente con respecto al plano del cuadro dejando la pared del fondo en posición frontal, de cuya superficie pende un cuadro. En esa pared un vano abierto descubre un espacio

${ }^{21}$ Hasta entonces la única escena de taller de pintor considerada digna de representación era el episodio de San Lucas retratando a la Virgen, popularizado a partir del siglo XV, tolerándose a veces de buen grado que el rostro del evangelista fuese el del propio pintor que ejecutaba la obra. Como apunta André Chastel, "en los Países Bajos protestantes, el tema de San Lucas cede su lugar al tema del pintor en su taller". Chastel, 2015: 41.

${ }^{22}$ Para algunos se trata del propio Martínez del Mazo mientras que para otros es su propio suegro Velázquez, aunque esto último no parece probable. 
más allá del escénico principal. La claridad exterior, algo mayor que la de la estancia, se atempera con la figura de un sirviente. El considerable volumen de la cama se alivia con un "fuera de cuadro". Y, considerada globalmente, la composición concede importancia a los planos constructivos, sobre todo al muro frontal y al suelo, a la vez que muestra la techumbre. Por último, el recorrido de la mirada describe, de izquierda a derecha, una pendiente en suave descenso -al igual que en Las Meninas- que, comenzando en los rostros de los personajes de la izquierda, continúa por la cabeza del artista y la zona central del grupo de invitados, acabando en la figura del pequeño a la derecha, el equivalente de Craesbeeck al Nicolasico de Madrid.

De entre otros muchos retratos de grupo neerlandeses, el Retrato de una familia tocando música (1663), de Pieter de Hooch, presenta un aspecto ya insinuado, y que conecta con el lienzo del Prado. En un interior doméstico la familia se ha reunido para practicar música. La señora ha advertido nuestra presencia y parece indicar, con la mano alzada, un alto a los demás. La mujer nos mira con atención al tiempo que la acción musical parece a punto de detenerse. Este efecto sorpresivo, que denuncia nuestra presencia y provoca la detención de la acción en proceso, lo habíamos encontrado ya en Retrato de la familia del pintor tocando música (hacia 1635), de Jan Miense Molenaer (Figura 1), en la que además la distribución de los personajes invita a un recorrido visual similar al descrito antes en el lienzo de Craesbeeck con relación al de Madrid. Idéntico efecto de sorpresa y detención temporal se observa en Los síndicos de los pañeros (1662), de Rembrandt van Rijn. En el retrato de grupo, género típicamente holandés, raramente los personajes dejan de sorprenderse por la presencia intrusiva del espectador. Y así, el plano del cuadro se convierte en membrana transparente que separa el espacio simulado del real, el del espectador, ampliando así la espacialidad total de la obra ${ }^{23}$. En cualquier caso, la advertida mirada hacia el espectador -de Margarita, Isabel de Velasco, Mari Bárbola, Velázquez, José Nieto y quizás los propios Felipe IV y Mariana de Austria- y la detención momentánea de sus acciones, están claramente presentes en el lienzo de Madrid. Pero al igual que sucede en los lienzos holandeses, en el del Prado tampoco la acción vital se detiene por completo, pues ni Agustina Sarmiento ni Marcela de Ulloa detuvieron aún sus impulsos. $\mathrm{Ni}$, por supuesto, Nicolasico, que ajeno a todos juega sin éxito a importunar el reposo de ese mastín español eternamente tendido a los pies del cuadro. De este modo, lo que los objetos parcialmente "fuera de cuadro" implican para la percepción de una "espacialidad extendida", así la desatención al espectador de ciertos

${ }^{23}$ Las Meninas, observada sin descanso por nutridos grupos de visitantes en el Prado, cuando se la mira desde detrás del público congregado ante ella nos produce el sugerente efecto de no saber exactamente quién observa a quién, pues el lienzo actúa a modo de membrana transparente entre una y otra dimensión espacial. 
personajes y la consiguiente continuidad de sus acciones suponen una suerte de "tiempo extendido" más allá del "tiempo detenido" general de la obra.

Aquello que hemos llamado "espacialidad extendida" se produce en Las Meninas por cuatro vías. La primera sería el objeto "fuera de cuadro"; la segunda, el vano abierto al fondo; la tercera, la mirada de los personajes al espectador, que conecta el espacio fingido con el espacio real; $y$, la cuarta, genialmente utilizada en el lienzo de Madrid, es el reflejo que registra, en el espejo de la pared, lo que existe más acá de la membrana del cuadro ${ }^{24}$. El motivo del espejo colgado en la pared es recurrente en la pintura neerlandesa barroca ${ }^{25}$, como en Enseñando a un niño a caminar (hacia 1670), de Pieter de Hooch, en el que el plano inclinado del espejo en la pared del fondo deja ver un espacio que se extiende por delante del plano del cuadro. O también en Interior con pintor, mujer leyendo y sirvienta limpiando (1668), de Pieter Janssens Elinga. Lo que hace Velázquez entonces, al igual que los pintores neerlandeses del XVII, es extender el concepto que de cuadro (escénico) era de uso en el teatro del Siglo de Oro ${ }^{26}$. Pues si por cuadro (escénico) se entendía "una acción escénica ininterrumpida que tiene lugar en un espacio y tiempo determinados" 27 , Velázquez y los holandeses conectaron aquella acción escénica principal, con un cuadro -sugerido, mediante el "fuera de cuadro", el vano abierto y el espejo-, y con otro cuadro -el de nuestro espacio real, mediante la mirada de los personajes-.

${ }^{24} \mathrm{Si}$ queremos entender que el reflejo de la pareja real no proviene del lienzo que Velázquez ejecuta, sino de algún lugar próximo al propio espectador.

${ }^{25}$ Para Michael Jacobs "the depiction of mirrors was common in painting at this time and earlier -most often in Flemish art" ("el uso de espejos fue común en la pintura de este momento y anteriormente. Más frecuentemente en el arte flamenco"). Jacobs, 2016: 3.

${ }^{26}$ En el capítulo "Velázquez, la Pintura y el Teatro del Siglo de Oro", en Estudios sobre Velázquez, Miguel Morán establece un interesante paralelismo entre la escena representada en Las Meninas y lo que acontece en los escenarios del teatro español de la época, especialmente en los espacios áulicos. Morán Turina, 2006: 96-99. En el primer capítulo del catálogo de la exposición Velázquez y la familia de Felipe IV (1650-1680), Javier Portús apunta que la temática del pintor ejerciendo su oficio tuvo predicamento en el teatro de público cortesano, el cual, "durante la década de 1650 tuvo múltiples oportunidades de ver a pintores realizando un retrato sobre el escenario". En 1651, sigue diciendo, Calderón estrena Darlo todo y no dar nada, una pieza que alude a "la relación entre Alejandro Magno y su pintor Apeles, que se había convertido en punto de referencia principal e ineludible de cualquier argumentación a favor de la dignidad del arte y que con frecuencia se ha extrapolado a la relación entre Felipe IV y Velázquez, e incluso a la propia obra maestra de este”. Portús Pérez, 2014: 27. Por su parte, André Chastel conecta el tono teatralizado de ciertas obras del barroco neerlandés con el teatro de Calderón, Thomas Middleton o Corneille, "donde el protagonista de la pantomima subraya, cuando quiere, el carácter ilusorio del espectáculo ficticio invitando al espectador a proyectar en ello su propia situación y, por consiguiente, aplicar a la vida la conciencia de la ilusión teatral”. Chastel, 2105: 38-41.

${ }^{27}$ Allen, 1996: 85. 
Otro recurso por el que se registra un acceso, más que a una "espacialidad extendida", a un "universo simulado" es el que se conoce como cuadro dentro del cuadro, donde el pintor reproduce pinturas, bien propias o de artistas reconocidos. Así aparece en multitud de ejemplos neerlandeses como complemento a escenas costumbristas, interiores domésticos, o retratos de grupo. De esta manera lo vemos en El archiduque Leopoldo Guillermo en su Galería de Bruselas (hacia 1649), de David Teniers el Joven, o en diversas pinturas de gabinete como las de Willem van Haecht y otros. En Gabinete del pintor (1623), de Frans Francken el Joven, la pintura de gabinete se funde con la de género, mostrando al pintor en pleno ejercicio rodeado de muros colgados de cuadros. De modo similar ocurre en Las Meninas. Pero en Velázquez los lienzos del fondo ${ }^{28}$ conectan narrativamente con la escena principal dotándola de significaciones ${ }^{29}$. Esa sinergia, producto del juego cruzado de elementos escénicos, sucede también, entre otros, en el lienzo del holandés Johannes Vermeer La tasadora de perlas (1664), en el que la representación del Juicio Final en el cuadro simulado y la balanza de platillos vacíos que la joven sostiene aluden al valor verdadero de las cualidades inmateriales, conectando así el cuadro simulado con la escena representada en el cuadro real. Por su parte, el neerlandés Frans Floris I, en Retrato de la familia Berchem (1561) (Figura 5), utiliza el recurso del cuadro colgado al fondo para dar constancia de la presencia virtual de un miembro no presente de la familia ${ }^{30}$. Al igual que vimos en el retrato de la dama en Tres mujeres ante el virginal (1634), de Molenaer. Así también Velázquez incorpora la presencia de Felipe IV y Mariana de Austria, fundiendo en uno el recurso del espejo como indicador de una "espacialidad extendida", y el recurso evocador de la presencia inmanente de unos miembros no presentes en escena.

Hicimos mención al paralelismo entre las escenas extemporáneas y moralizantes que Velázquez incluye en sus lienzos tempranos, y aquellas otras en las escenas de cocina de la pintura neerlandesa meridional, como Cristo y la mujer adúltera (hacia 1557), de Pieter Aertsen, o La cocina bien provista (1566), de Joachim Beuckelaer. Velázquez nunca dejó de usarlas, como haría en Las hilanderas (hacia 1657). Son precisamente esas escenas extemporáneas las que, junto a otros elementos escenográficos, infunden pleno sentido a la obra. Podríamos

${ }^{28}$ Los cuales, precisamente, son copias de Martínez del Mazo a partir de originales de Rubens y Jordaens, pintores neerlandeses.

29 Una conexión narrativa que ha sido señalada, entre otros expertos, por Julián Gállego. Gállego, 1990: 427-428.

${ }_{30}$ Así lo expresa André Chastel al decir que, en la pintura neerlandesa, "el retrato insertado en medio de la tela hace presente al ancestro desaparecido y concluye en cierta forma el sistema genealógico". Chastel, 2015: 23-24. 
concebirlas como fantasmagorías ${ }^{31}$ que influyen, con su potencial aleccionador, en la escena principal transmutándola en alegoría. Cabría plantear si no es eso lo que sucede en el lienzo del Prado, siendo la imagen especular una imagen aleccionadora que insufla sentido en la escena ${ }^{32}$, a la par que una encarnación de la pareja real. Es decir, la unificación ahora de tres recursos diferentes: la fantasmagoría $^{33}$, el retrato efigiado y el espejo.

Una última comparación entre el lienzo de Madrid y la pintura neerlandesa es ahora preceptiva, y es la factura pictórica. Principalmente lo que llamaremos "gesto pictórico", es decir, esa especie de movimiento, de coreografía, que en forma de huella pictórica el pincel dibuja sobre la tela y que supone -desde lo puramente pictórico- un deleite principal en la obra velazqueña. Si comparamos el "gesto pictórico" de Frans Hals, holandés de adopción ${ }^{34}$, con el de Velázquez podemos ver que a pesar de las diferencias ejecutorias ${ }^{35}$ entre el neerlandés

31 Juan José Martín González, en el artículo "La habitación en el espacio de Velázquez”, en Reflexiones sobre Velázquez, considera la tendencia de Velázquez al equívoco aduciendo que "conocía todos los recursos de la literatura contemporánea. El equívoco fue precisamente una de las modalidades cultivadas por los escritores del siglo XVII. Supone que no se sepa claramente lo que sea una cosa, pues puede ser lo que a primera vista parece o todo lo contrario”. Martín González, 1992: 81.

${ }^{32}$ Para Víctor Nieto, "el hecho de que los reyes aparezcan reflejados en un espejo no se debe a un ingenioso juego perspectivo. El espejo no refleja un fragmento de realidad. Es un recurso para plasmar su presencia sin representarlos en escena. [...] Es una forma de atestiguar la presencia del soberano y, al mismo tiempo, de mantenerlo oculto, según un ritual áulico establecido”. Nieto Alcalde, 2008: 72-73.

${ }^{33}$ Refiriéndose a la imagen reflejada en el espejo, Muller habla del "ingenioso artificio que da mucho peso a lo que apenas lo tenía y convierte en fantasmas evanescentes a estos personajes cuya existencia real se imponía a todo el mundo" (la cursiva es nuestra). Muller, 1975: 231. Y Gállego nos avisa del reflejo sobre la coraza del Juicio Final (1466), de Memling, donde la "apariencia falsa dentro de la apariencia falsa del cuadro, reflejo en el reflejo, espejo en el espejo, nunca el «cuadro dentro del cuadro» adquiere un sentido más desengañado y, al mismo tiempo, más seductor que cuando nos miente doblemente". Gállego, 1978: 111.

${ }^{34}$ Aunque natural de Amberes, Frans Hals abandonará siendo aún un niño su ciudad de origen para instalarse definitivamente y hasta su muerte en Haarlem.

${ }^{35}$ Velázquez gusta de combinar en el mismo lienzo amplias zonas de veladura con áreas localizadas de mayor empaste. En ello percibimos, como es sabido, una influencia veneciana, sobre todo ticianesca. Por su parte, Frans Hals empasta la superficie del lienzo de modo más homogéneo. En los retratos de Velázquez, incluyendo los de Las Meninas, las cabezas presentan un tratamiento más detenido o reposado -sin menoscabo de solturaque el resto de la figura, ya sean cabellos, medallones, ropajes u otros elementos donde el pintor despliega su gestualidad pictórica. El efecto es peculiar pues centra el interés, sin obligarlo, en las cabezas de los retratados. El gesto pictórico es, por tanto, en los elementos no centrales de la figura, de mayor soltura y amplitud, y como consecuencia más rico y 
y el español, ambos comparten una suerte de impulso esencial que les conduce a ejecutar sobre las superficies de sus lienzos una danza pictórica cuyas huellas, cuyos trazos, declaran su parentesco estético; una grafía pictórica hermanada tal, que hace difícil negar la influencia que de uno puede ser reconocida en el otro. En Las Meninas, las amplias áreas de silenciosa quietud contrastan con otras donde las tensiones del pincel propician una intensa dinamicidad del "gesto pictórico", como en el realce sobre el pecho de la infanta Margarita (Figura 6), en su manga izquierda, en la basquiña que desde el jubón descansa en el guardainfante, o en los toques de luz del bordado del mismo; también en las contramangas de Isabel de Velasco o en el lazo rojo de su muñeca izquierda; y en las contramangas del propio pintor. Hemos destacado estas zonas de entre otras igualmente soberbias porque queremos distinguir en Velázquez dos modos de gestualidad pictórica, igualmente gráciles y expresivos. A uno le llamaremos "gesto incisivo", mientras al otro nos referiremos como "gesto dúctil" ${ }^{36}$. Son de "gesto incisivo" los citados más arriba, muy próximos a la manera de hacer de Frans Hals. El "gesto dúctil" se manifiesta deliciosamente en el motivo hexagonal del lateral del guardainfante de Agustina Sarmiento, en las franjas bordadas de la basquiña de Mari Bárbola, o en los espléndidos y fugaces reflejos en la zona derecha de la basquiña de Isabel de Velasco. Si comparamos las gestualidades "incisivas" de Velázquez con la pincelada de Hals, el parentesco es evidente. Así lo vemos en Hals en el recogido de las fajas de los personajes de primer plano en Reunión de oficiales y sargentos de la caballería municipal (1633). O también en Familia ante un paisaje (hacia 1646), especialmente en el guante y la bocamanga del brazo izquierdo de la muchacha o en la lazada ornamental que abrocha la toquilla que cubre sus hombros, y en la botonadura de entrelazo que cierra la chaquetilla del muchacho (Figura 7). La misma pincelada de aire velazqueño, gestual, decidida y enérgica, la encontramos también en el plegado de la manga izquierda de La chica gitana (1628), también de Frans Hals (Figura 8).

El conjunto de similitudes entre la producción neerlandesa del Siglo de Oro y el lienzo de Las Meninas no puede ser el producto de una coincidencia, apelando a un "supraestilo" que, sin embargó, no afectó al conjunto de la producción pictórica de la España del XVII. El grueso de circunstancias presentadas aquí hubo de tener como fuente la estampación seriada, común a la época. Pero la influencia

jugoso. En el caso de Hals, el impulso técnico es diferente pues trata pictóricamente al personaje como un todo unitario, expresando su gestualidad con mayor uniformidad que Velázquez, y utilizando una técnica pictórica de mayor cubrición a causa de su menor apego a la veladura.

${ }^{36}$ Por "gesto incisivo" queremos aludir a una pincelada decidida y resuelta, de recorrido relativamente corto, de itinerario preferentemente rectilíneo, y de gran efecto. El "gesto dúctil" se entrega a itinerarios orgánicos de una mayor voluptuosidad, más sensuales, aunque igualmente de gran efecto y expresividad. 
gestual, puramente pictórica, solo pudo originarse por la observación directa de los lienzos originales. Sobre las oportunidades que Velázquez hubiese podido tener de conocer la obra de Hals, a la sazón diecisiete años mayor que él, nada sabemos documentalmente. Ni del acercamiento del pintor a la producción neerlandesa de su momento. Pero la intensidad del comercio artístico entre los Países Bajos e Italia en el siglo XVII ${ }^{37}$, junto a la profunda conexión de la corona española con la Italia del seiscientos, bien hubiera podido procurar a la innata curiosidad del pintor español el conocimiento del panorama artístico del septentrión europeo. No olvidemos, además, que una gestualidad pictórica renovada aparece en la obra velazqueña justamente tras el regreso de su primer viaje a Italia ${ }^{38}$.

En definitiva, y recapitulando, digamos que existen al menos diez razones que apuntan hacia una influencia neerlandesa en el lienzo de Las Meninas de Velázquez.

La primera sería el tratamiento espacial: el volumen cúbico y simplista de la estancia; la ortogonalidad o -según proceda- paralelismo de las aristas de los planos constructivos con respecto al plano del cuadro; la ordenación en retícula ortogonal de los elementos (cuadros, espejo, puertas) en el muro de fondo; la importancia dada a la presencia de los planos constructivos (muros, techo); y la puerta abierta al fondo, que por sí sola merece consideración aparte.

La segunda circunstancia es, entonces, la puerta abierta al fondo, que conectando los espacios cercano y lejano crea la ilusión de una realidad más allá del ámbito escénico principal.

La tercera sería la figura del aposentador, que sugiere una profundidad perspectiva mediante la relación entre sí misma y el grupo en primer plano. Su silueta atempera además el golpe de luz enmarcado por el umbral. Y a la vez conecta narrativamente, a tenor del gesto de José Nieto, lo que sucede entre los dos espacios de los que el muro de fondo es frontera.

La cuarta circunstancia viene dada por una intención de "espacialidad extendida". Proporcionada por los elementos "fuera de cuadro" (lienzo, caballete, contraventana y Nicolasico); por la puerta abierta que advierte de una realidad más allá; por el espejo, que declara mediante el reflejo una realidad más acá de la membrana del cuadro; y por la integración de nuestro propio espacio real mediante la mirada cómplice de los personajes.

La quinta la supondría la percepción de una especie de "tiempo extendido" que se produce por el contraste entre la interrupción escénica de ciertos personajes

37 Juan María Cruz Yábar nos da cuenta, en su artículo acerca del lienzo Judit en el banquete de Holofernes de Rembrandt -cuya Judit él identifica con Ester-, de la intensidad de ese comercio artístico. Cruz Yábar, 2013.

${ }_{38}$ Para José Gudiol, esa evolución gestual se inaugura al año siguiente de su vuelta del primer viaje a Italia con El príncipe Baltasar Carlos (1632) y se manifiesta especialmente en Felipe IV de castaño y plata (hacia 1632), donde el pintor pasa a una "fase más desmaterializada pero igualmente precisa en el dibujo”. Gudiol, 1982: 142-143. 
-los que nos miran- y la despreocupada continuación escénica de otros -los que nos ignoran-.

La sexta viene dada por el espejo en la pared. Velázquez lo utiliza quizá para dar cuenta de un espacio por delante del plano del cuadro, el del espectador. Pero también se corresponde con aquellas fantasmagorías extemporáneas de carácter moralizante al gusto de la pintura flamenca de los siglos XVI y XVII, insuflando entonces en la escena principal un matiz significativo. Y además Velázquez, en una vuelta de tuerca, utiliza la imagen especular de los monarcas para dar fe de su condición de omnipresencia.

La séptima circunstancia se manifiesta en el uso de un género, el del retrato de grupo, tan extraño a la España del seiscientos como afín a los Países Bajos. En tales retratos colectivos, la mirada de los personajes declara el efecto invasivo de la presencia del espectador.

La octava es la temática del pintor autorretratado en pleno ejercicio de su profesión, tan insólita en la tradición española seiscentista como usual en la neerlandesa.

La novena comporta el gesto del pincel. Tan próximo el de Velázquez al de los grandes artistas de los Países Bajos ${ }^{39}$-en especial Frans Hals- que bien pudieron serle de influencia.

Y en décimo y último lugar cabría considerar la posible curiosidad, o simpatía, que Velázquez hubiera podido albergar por una ideología -la reformista- no ya extraña, sino prohibida en la España de su tiempo. La austeridad y reserva de Velázquez, su notorio desapego por la temática y ampulosidad contrarreformistas, su elogio a la dignidad del individuo -como en aquella sobrecogedora humanidad de El Niño de Vallecas- y, en fin, todas las afinidades estéticas y narrativas que han sido relacionadas, bien pudieran haber llevado aparejadas no solo un interés meramente estilístico y compositivo sino quizás un cierto posicionamiento intelectual.

Fecha de recepción: 11 de octubre de 2019

Fecha de aceptación: 13 de abril de 2020

39 Alejandro Vergara, comisario de la exposición Velázquez, Rembrandt, Vermeer. Miradas afines, celebrada en el Museo del Prado en 2019, conecta la gestualidad pictórica de Velázquez no solo con Hals, sino también con la de otros pintores neerlandeses como Rembrandt. Vergara, 2019. 


\section{BIBLIOGRAFÍA}

Alarcó, Paloma (2012): Mondrian, De Stijl y la tradición artística holandesa. Madrid: Museo Thyssen-Bornemisza.

Allen, John J. (1996): "La división de la Comedia en Cuadros". En: En torno al Teatro del Siglo de Oro. Almería: Instituto de Estudios Almerienses, pp. 85-94.

Bardi, P. M. (1973): La obra pictórica completa de Velázquez. Barcelona: NoguerRizzoli.

Chastel, André (2015): El cuadro dentro del cuadro. Madrid: Libros de la resistencia.

Cruz Yábar, Juan María (2013): “Judit o Ester? El Rembrandt del Museo del Prado". En: Anales de Historia del Arte, 23, pp. 99-112.

D’Ors, Eugenio (2002): Lo Barroco. Madrid: Alianza.

Gállego, Julián (1978): El cuadro dentro del cuadro. Madrid: Cátedra. (1990): “Catálogo". En: Velázquez. Madrid: Museo Nacional del Prado, pp. $57-456$.

Gudiol, José (1982): Velázquez. 1599-1660. Barcelona: Ediciones Polígrafa.

Harris, Enriqueta (2006): Estudios completos sobre Velázquez. Madrid: Centro de Estudios Europa Hispánica, CEEH.

Jacobs, Michael (2016): Everything is Happening. Journey into a Painting. London: Granta.

Martín González, Juan José (1992): “La habitación en el espacio de Velázquez”. En: Reflexiones sobre Velázquez. Madrid: Real Academia de Bellas Artes de San Fernando, pp. 71-94.

Morán Turina, Miguel (2006): Estudios sobre Velázquez. Madrid: Akal.

- (2010): La escalera de las Descalzas Reales de Madrid. Madrid: Universidad Complutense.

Muller, Joseph-Emille (1975): Velázquez. Madrid: Daimon.

Nieto Alcalde, Víctor (2008): "Velázquez, el cuadro oculto y la metáfora del espejo". En: Espacio, Tiempo y Forma, 20-21, pp. 57-83.

Novero Plaza, Raquel (2007): "La familia de Juan Bautista Martínez del Mazo, yerno de Velázquez. Consideraciones sobre los personajes del cuadro La familia del pintor". En: Boletín del Seminario de Arte y Arqueología, 72-73, pp. 177-191.

Palomino, Antonio (1796): “El Parnaso Español Pintoresco Laureado”. En: El Museo Pictórico y Escala Óptica. Madrid: Imprenta de Sancha, pp. 347-734.

Portús Pérez, Javier (2013): Velázquez y la familia de Felipe IV (1650-1680). Madrid: Museo Nacional del Prado.

Vergara, Alejandro (ed.) (2019): Velázquez, Rembrandt, Vermeer. Miradas afines. Madrid: Museo Nacional del Prado. 


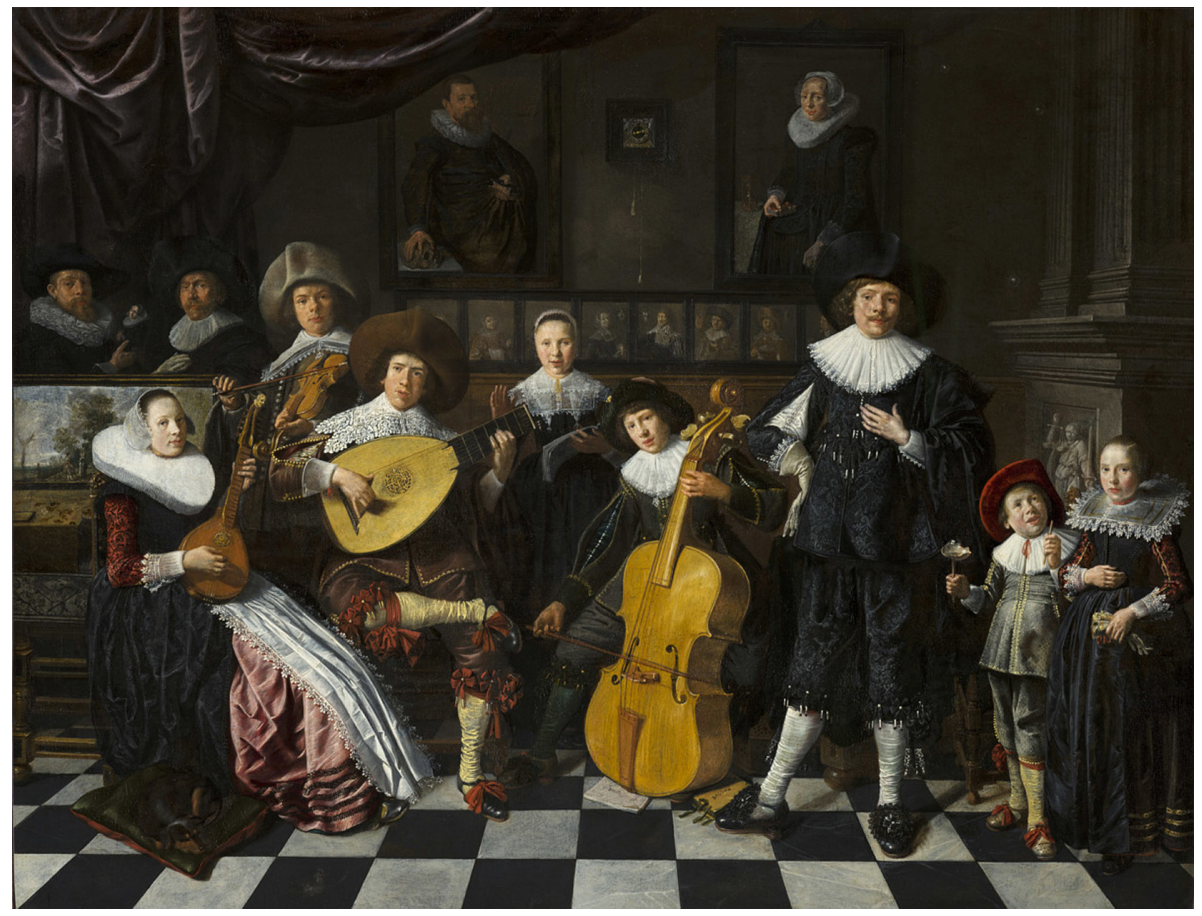

Figura 1. Jan Miense Molenaer, Retrato de la familia del pintor tocando música, hacia 1635, Frans Hals Museum, Haarlem. INV. os 75-332 NK3048. 


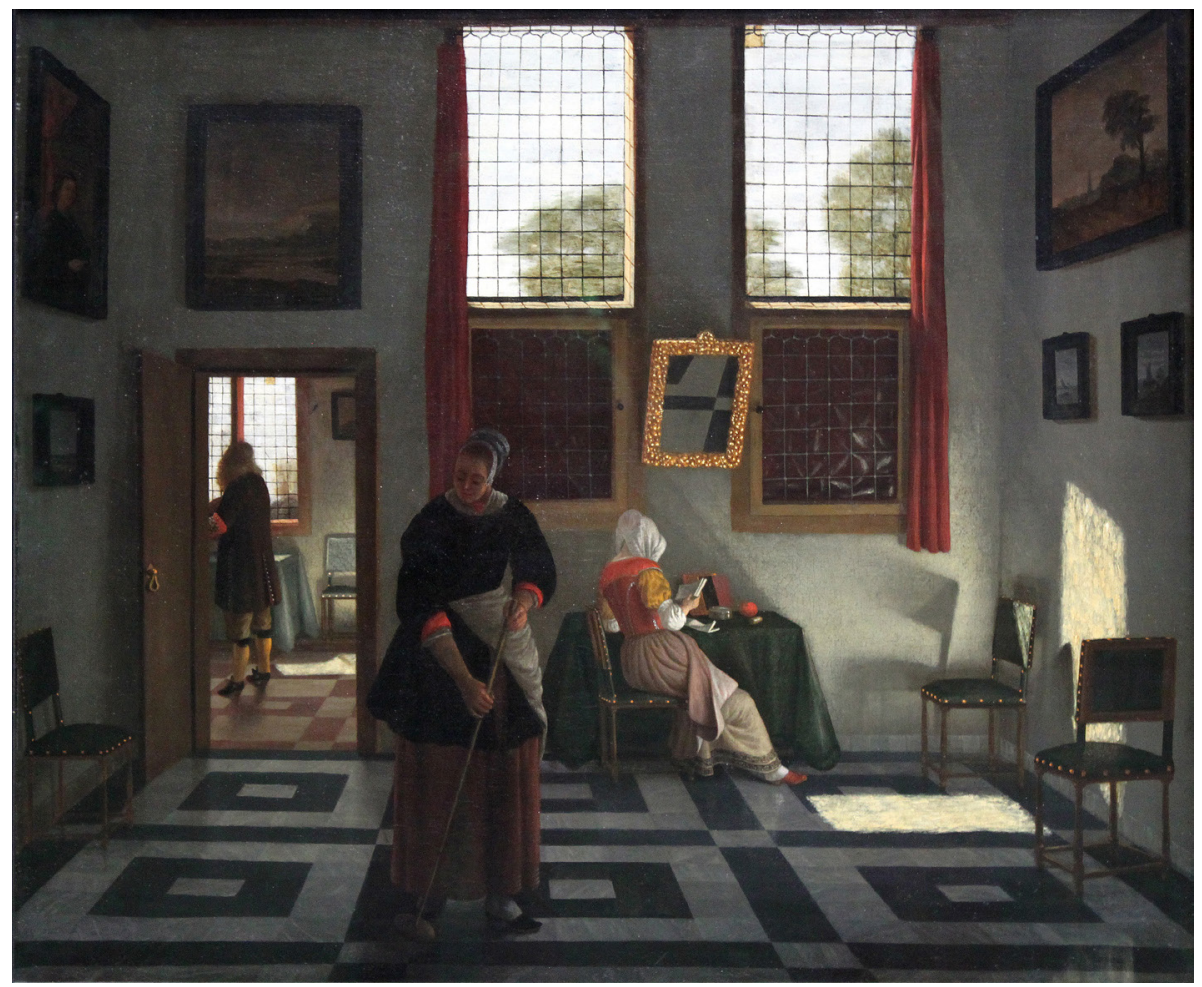

Figura 2. Pieter Janssens Elinga, Interior con pintor, mujer leyendo y sirvienta limpiando, 1668, Städelsche Kunstinstitut und Städtische Galerie, Frankfurt. INV. 1129. 


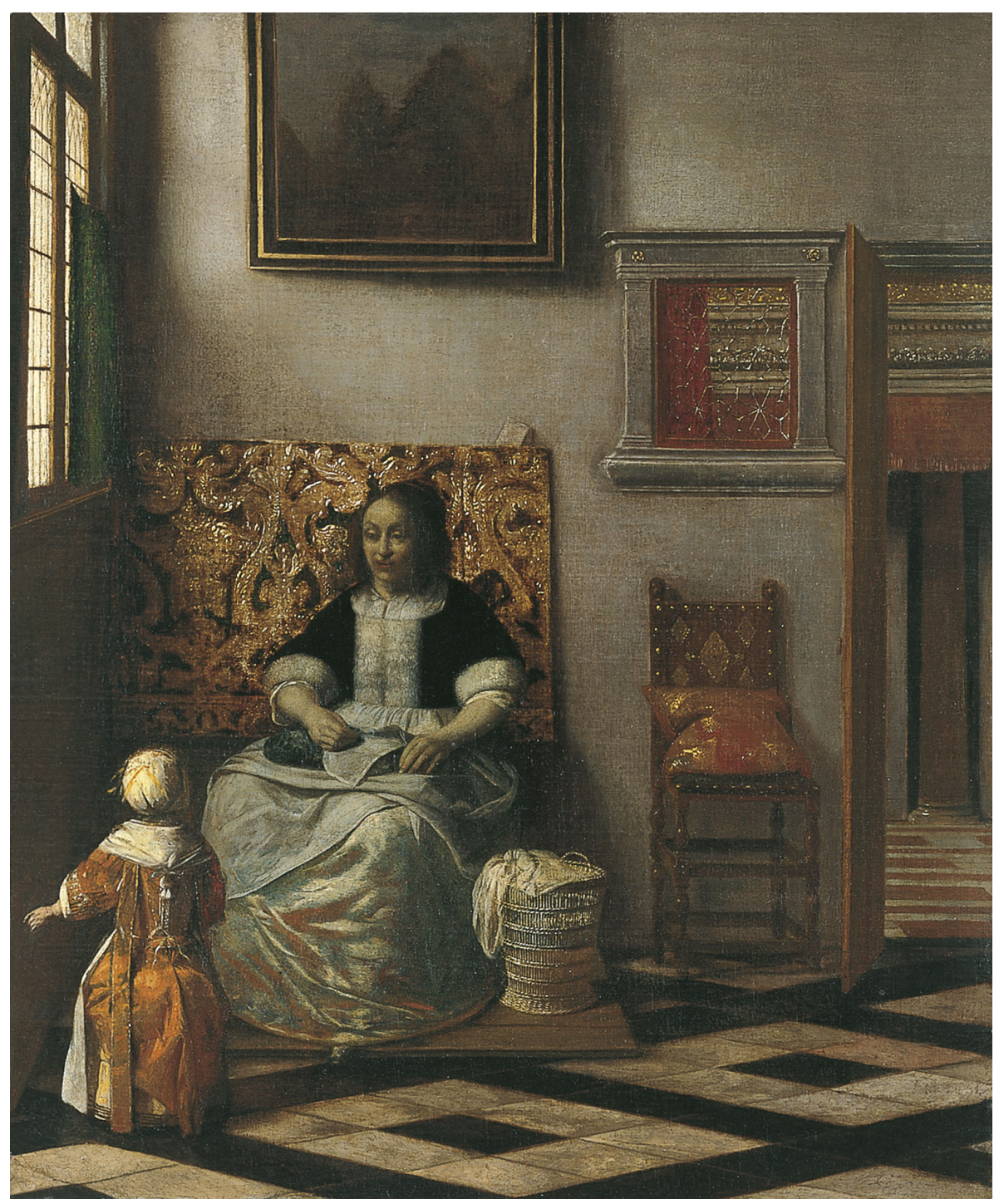

Figura 3. Pieter de Hooch, Interior con mujer cosiendo y niño, hacia 1668, Museo Nacional Thyssen-Bornemisza, Madrid. INV. 195 (1958.7). 


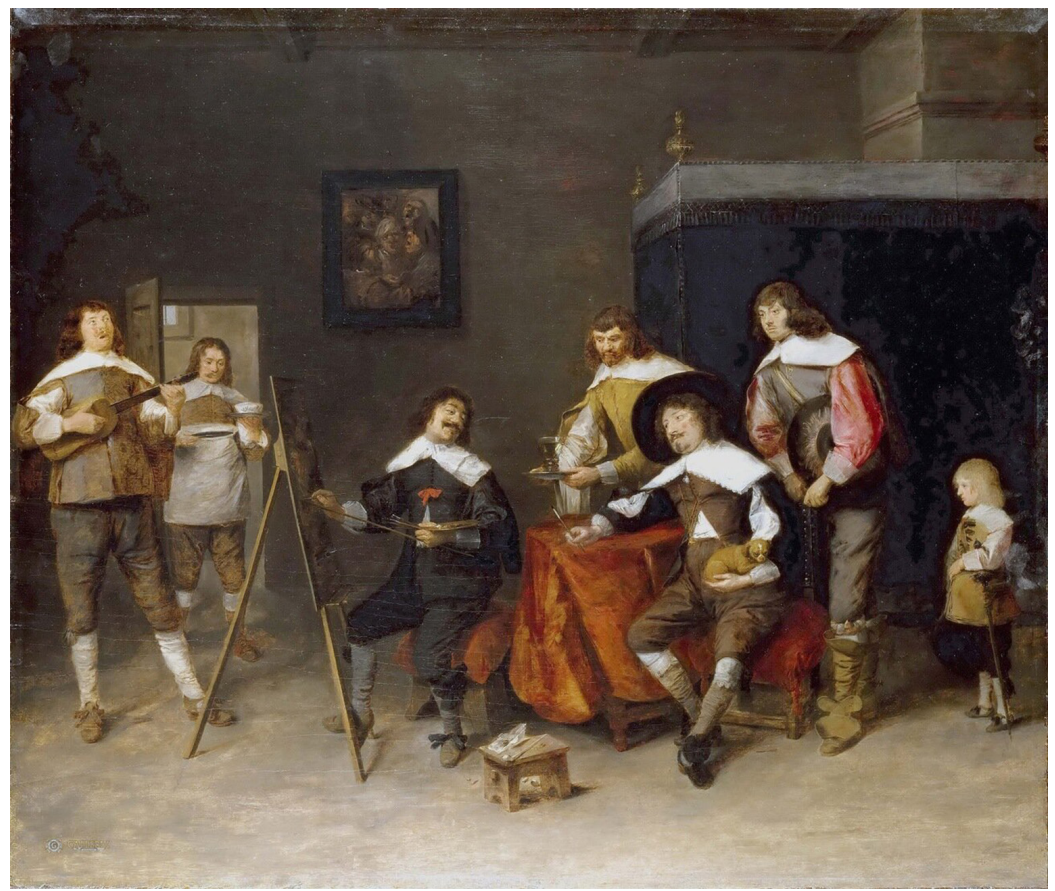

Figura 4. Joos van Craesbeeck, Pintor pintando un retrato, 1600-1650, Musée du Louvre, París. INV. 1179.

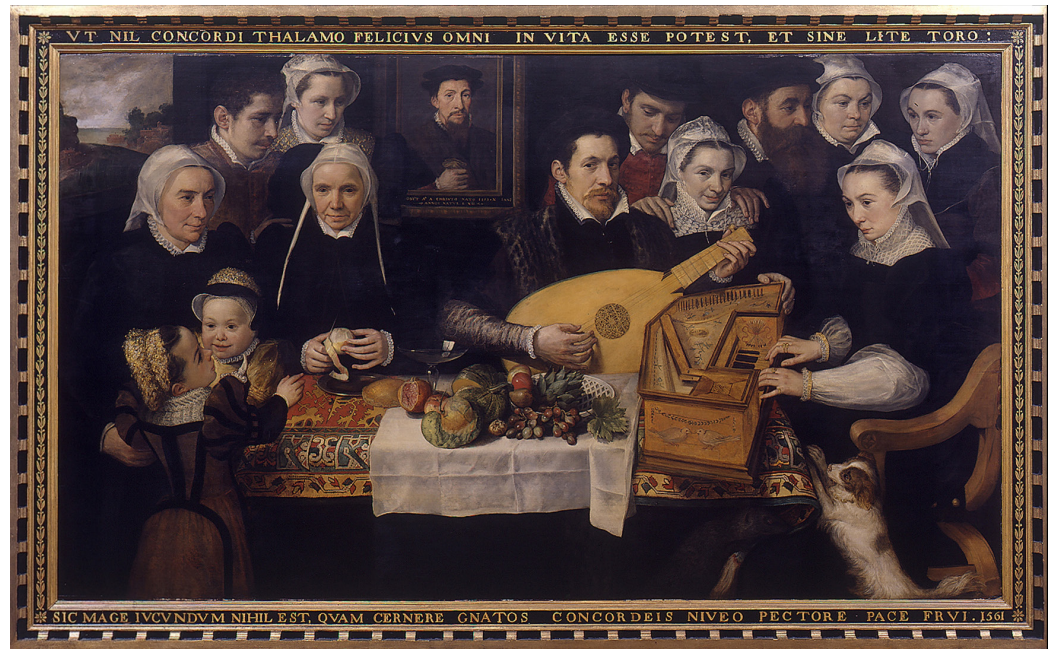

Figura 5. Frans Floris I, Retrato de la familia Berchem, 1561, Stedelijk Museum Wuyts-Van Campen en Baron Caroly, Lier. INV. nr 52. 

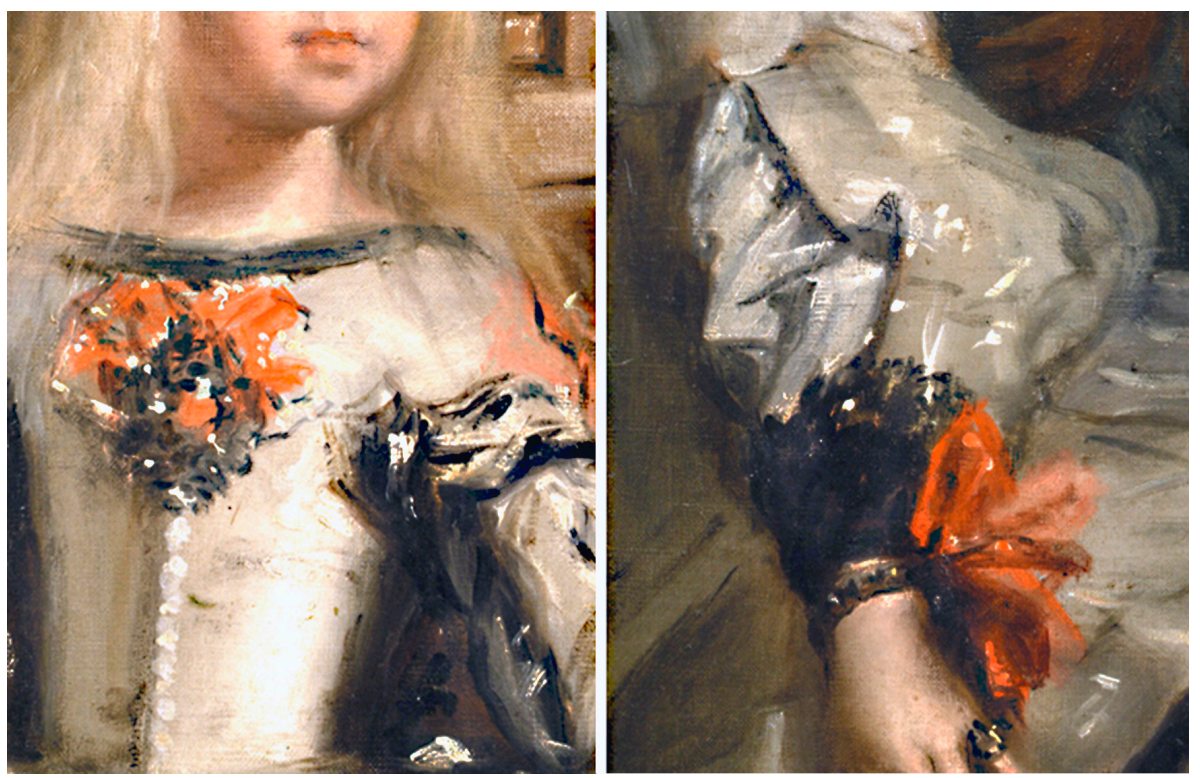

Figura 6. Diego Velázquez, Las Meninas (detalles), 1656, Museo Nacional del Prado, Madrid. INV. P001174.
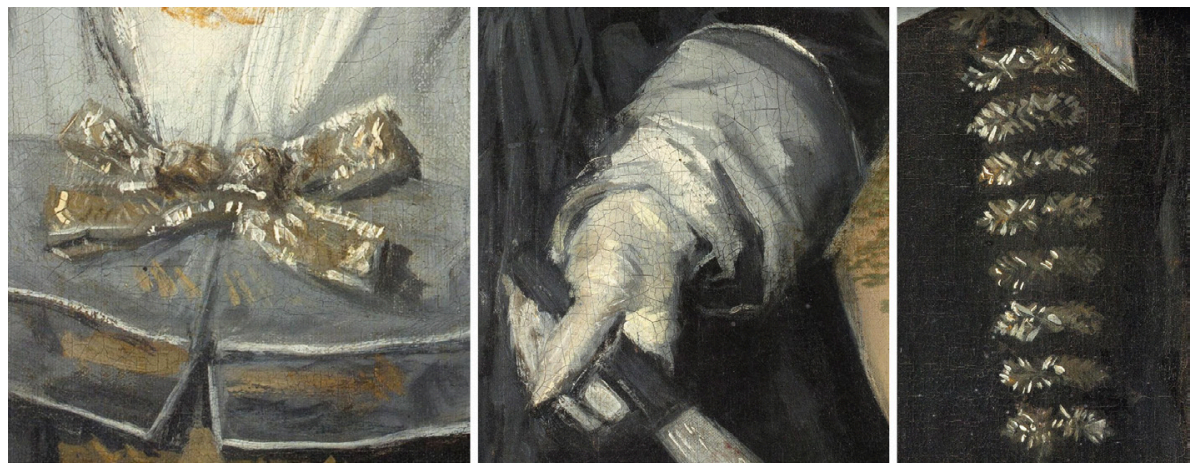

Figura 7. Frans Hals, Familia ante un paisaje (detalles), 1633, Museo Nacional Thyssen-Bornemisza, Madrid. INV. 179 (1934.8). 


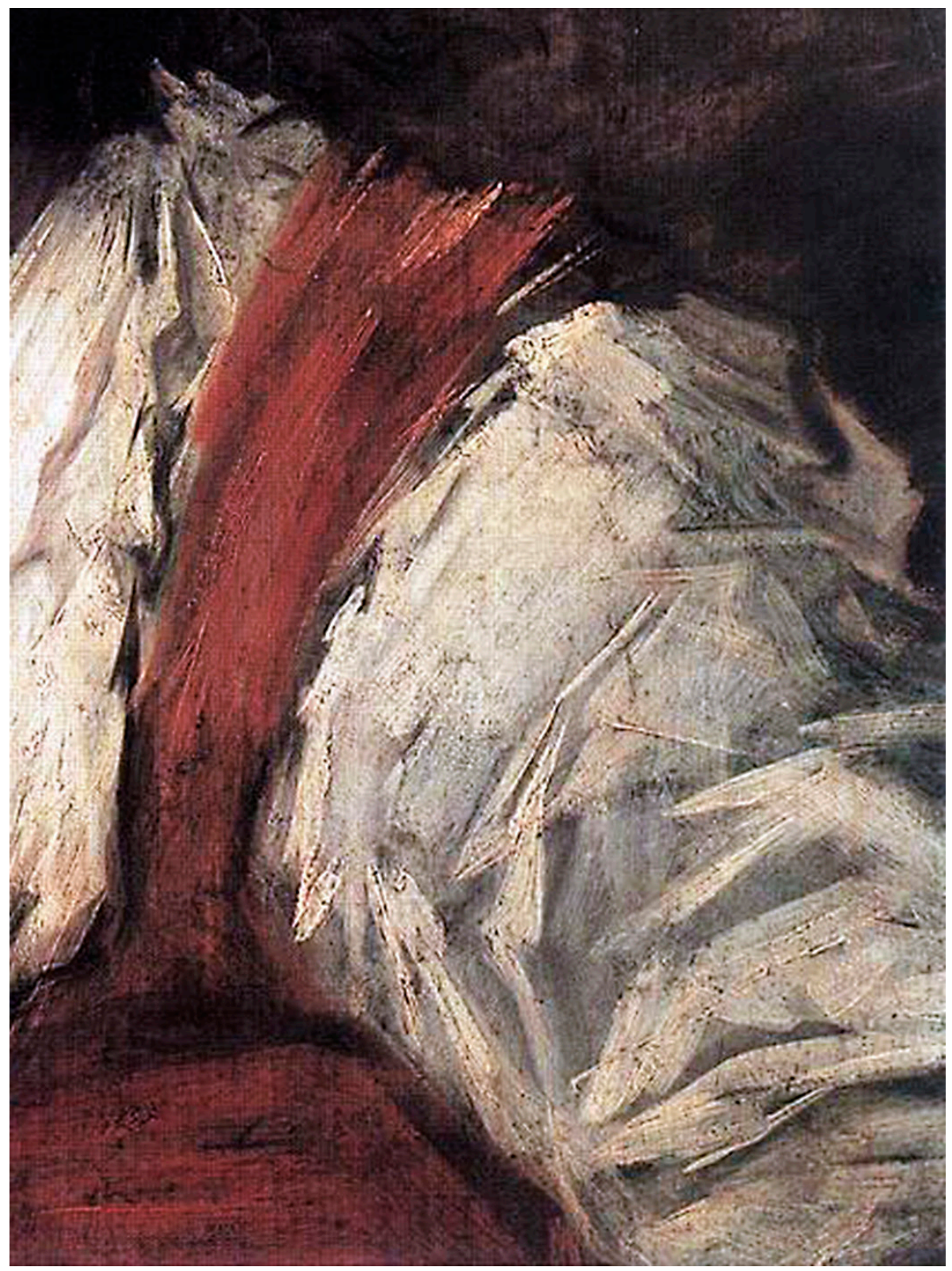

Figura 8. Frans Hals, La chica gitana (detalle), 1628, Musée du Louvre, París. INV. MI 926. 